\title{
Employment Effects of Technological Innovation in Korean Manufacturing Firms: by using PSM
}

\author{
Taeyang Kim \\ Researcher, Trend Information Room, \\ Science and Technology Policy Institute
}

\begin{abstract}
This study examines the impact of technological innovation by Korean manufacturing companies on employment using the 2012-2016 Korean Innovation Survey(KIS) by the Science and Technology Policy Institute(STEPI) and KisValue data obtained from NICE Information Service. While there have been many previous studies on this topic, none have taken the differences between individual businesses into consideration when estimating the effects of technological innovation by companies on employment. Accordingly, this study aims to use the PSM(Propensity Score Matching) method to control the selection bias that may occur due to the different characteristics of individual companies. Each analysis was carried out according to company size, while considering the characteristics of the Korean market. Also, in order to compare the differences of employment effects in each industry, the manufacturing industry was analyzed by dividing it into technology-intensive ICT and non-technology-intensive non-ICT sectors. Furthermore, the effects of product innovation and process innovation, in addition to technological innovation, on employment were examined. As a result, it was found that there were some numerical differences in employment effects according to technological innovation depending on the matching method, but there were positive $(+)$ effects for all companies. In addition, non-ICT companies displayed a higher number of positive $(+)$ employment effects compared to ICT companies. Product innovation had a positive $(+)$ impact on employment, while process innovation was found to decrease (-) employment in all results, with the exception of large conglomerates. In conclusion, of the technological innovations, product innovation was found to have a positive impact on employment, and therefore, it has policy implications, in that new product development or improvements to existing products are needed to improve the efficiency of the government's $R \& D$ policies.
\end{abstract}

Key words: Korea Business Innovation Survey(KIS) , technological innovation, employment effect, selection bias, Propensity Score Matching(PSM)

\section{INTRODUCTION}

According to the theory of economic growth, growth that depends only on the additional input of production factors such as labor and capital has reached its limit. This is the reason why technological innovation is essential for sustainable growth. Many countries are continuously making efforts to improve their productivity. In other words, the governments in each country are actively promoting investment in R\&D for technological innovation in recognition of the importance of productivity improvement for sustainable growth and the improvement of people's standard of living.

On the other hand, the debate over the impact of technological innovation on employment has been going on for quite some time. This is because technological innovation can have doubleedged effect on employment, both increasing and reducing employment. In Korea and other countries, the economy has grown rapidly due to technological innovation, but the problem of "jobless growth" has arisen as the employment creation effect was limited. In addition, 
employment is becoming one of the most important policy tasks of the government as companies go abroad, resulting in job cuts.

In academia, the relationship between technological innovation and employment has been actively researched to reflect the trends of the time. The relationship between technological innovation and employment, however, cannot be easily concluded. There are conflicting views on the impact of technological innovation on employment: some people claim that it reduces employment (Zimmerman, 1991; Aghion and Howitt, 1994; Michelacci and Lopez-Salido, 2007), while others claim that it increases employment (Vivarelli, 1996; Evangelista, Pissarides, 2000, Savona, 2003, Verspagen, 2004, Harrison et al., 2008; Lachenmaier and Rottmann, 2011). ${ }^{2)}$

Technological innovation can be generally divided into two categories: one is related to improvement and development of products and process innovation, and the other is associated with improvement and changes in production methods according to their characteristics (Utterback \& Abernathy, 1975). Many previous studies have shown that product innovation positively affects employment, which is due to "demand enlargement," in which new products increase demand (Moon and Jeon, 2008). The effect of process innovation on employment is less clear than in product innovation. This is due to the "labor displacement effect" causing a negative effect or a less positive effect on employment than product innovation (Vivarelli, 1996). For example, if a company's cost savings leads to a price drop, then demand may increase as prices fall, positively affecting employment. On the other hand, depending on the structure of the market, process innovation can have a negative effect on employment (Moon and Jeon, 2008). Thus, from a theoretical point of view, each case of innovation is assumed to have some effects (positive (+) or negative (-) on employment, but it is hard to accurately determine the net effect. In other words, the effect of technological innovation on employment is "uncertain," which leads to the topic of empirical analysis.

It is not easy to estimate the net effect of technological innovation on employment. This is because selection bias can be a factor due to the unique characteristics of individual companies. For example, individual companies may experience different employment effects depending on characteristics other than technological innovation, such as business type, size, assets, and access to government subsidies. In many previous studies, the effects of technological innovation and employment are focused only on labor productivity, and the problems of selection bias that can be generated due to unique characteristics of individual companies are overlooked. To address this issue, this study conducted an analysis using PSM (Propensity Score Matching) to control for the endogeneity that can occur within the two groups (treatment group and control group), focusing on the heterogeneity of observable individual companies. This is an effective way to solve the problem of selection bias when measuring the treatment effect (Blundell \& Costa-Dias, 2009).

In the rest of this study, we will examine previous studies in Chapter II, and examine the causes and matching theories of selection bias in Chapter III. Chapter IV explains the variables used in the study and the characteristics of the variables. Chapter $\mathrm{V}$ describes the results of the empirical analysis, and Chapter VI proposes conclusions and implications based on the results of the study, and then suggests future research directions.

2) The arguments are divided into two groups: those who think that technological innovation reduces employment by the emergence of new products, capital substituting for labor, price rigidity, and lack of aggregate demand, etc., and those who claim that technological innovation increases employment by increasing income and demand. 


\section{PREVIOUS STUDIES}

Previous studies analyzing the impact of technological innovation on employment have different views that are largely divided into two major camps: one asserts that technological innovation reduces employment and research, and the other claims that technological innovation increases employment. According to the research suggesting that technological innovation increases employment, unemployment occurs (creative destruction effect) as capital productivity substitutes for labor productivity when the innovation is embodied in capital. In the long run, however, thanks to increased production, incomes rise and savings and investment increase, recovering employment rate to the previous level or even increasing it (Caballero and Hammour, 1997). Mortensen and Pissarides (1998) argued that technological innovation promotes the entry of new operators and facilities, thus creating the so-called capitalization effect of reducing unemployment. Pissarides (2000) argued that innovation increases productivity and, as a result, firms increase employment by offering higher wages. Jaumandreu (2003) and Peters (2004) have used OLS to show that product innovation has a positive (+) effect, while process innovation has no significant impact, based on the European Community Innovation Survey(CIS III) data. Lachenmaier and Rottmann (2011) reported the positive $(+)$ effects of both product innovation and process innovation using Fixed Effect, using the data from Germany's corporate unit panel (1981-1991). Evangelista and Vezzani (2011) analyzed the data from the European Community Innovation Survey (CIS IV) using 3 Stage Least Squares (3SLS) regression and argued that innovation has a positive (+) effect on employment. Several previous studies in Korea have also suggested that technological innovation has a positive (+) effect on employment.

Bae et al. (2006) analyzed the employment inducement effect of technological innovation divided by industry. As a result, the high technology industry showed a continuous increase in employment, and the low technology industry showed a decrease in employment. By industry size, employment growth continued in small firms, while employment declined in large firms. However, it was argued that among the large enterprises, companies belonging to the hightechnology industry showed an increase in employment. Ha (2005) argues that technological innovation increases employment by reducing structural unemployment. Kang (2006) reported that technological innovation increases employment and output as well as labor productivity. Shin et al. (2012) used the dynamic employment model to argue that product innovation did not have a statistically significant effect on employment, and that process innovation positively affects corporate employment.

In contrast to the above logic, there are arguments that technological innovation reduces employment. The traditional hypothesis on the claim that technological innovation reduces employment is based on the creative destruction process theory proposed by Schumpeter, which causes the emergence of new products and labor displacement by capital. When new technology emerges, new products are invented to replace existing ones. Then, the demand for labor in the sectors that produced the existing commodities decreases, and the volume of employment decreases. Zimmerman (1991) conducted an empirical analysis based on the probit model using 16 industrial data from Germany, and explained that innovation results in a negative (-) effect on employment. Aghion and Howitt (1994) argue that technological innovation creates and cuts employment at the same time because workers no longer need the skills they possess when the pace of technological innovation speeds up. Michelacci and Lopez Salido (2007) also argue that technological innovation is the result of creative destruction, resulting in the elimination of companies that are not competitive and that these factors result in a decline in employment. 
As the many previous studies cited above suggest, there is a lack of empirical and consistent opinion on the impact of technological innovation on employment. In other words, the net effect of innovation on employment depends on various factors, which prevents us from reaching easy conclusions. Furthermore, the importance of technological innovation and job creation is growing in our modern society, in which the speed of technological innovation is increasing rapidly. As such, there is a need for supplementary research that can serve as a solution for the long-lasting low-growth trend.

\section{Problem of selection bias}

\section{STUDY METHOD}

When $Y_{1}$ and $Y_{0}$ are the probabilities that affect the enforcement of company's technological innovation, the variables for each of these companies can be expressed as $Y_{1 \mathrm{i}}$ and $Y_{0 \mathrm{i}}$. $\mathrm{D}_{\mathrm{i}}$ can be expressed as a dummy variable indicating whether technological innovation is active or not (Companies engaged in innovation activities: 1, Companies not engaged in innovation activities: 0). The following Equations (1), (2), and (3) show the effects of companies on innovation activities.

$\mathrm{Y}_{\mathrm{i}}=\beta \mathrm{X}_{\mathrm{i}}+\alpha \mathrm{D}_{\mathrm{i}}+\varepsilon_{\mathrm{i}}$

(2) $Y_{i}=Y_{0 i}=\beta X_{i}+\varepsilon_{i} \quad, D_{i}=0$

(3) $\quad Y_{i}=Y_{1 i}=\beta X_{i}+\alpha+\varepsilon_{i}, D_{i}=1$

In general, the treatment effect is defined as the difference between the "performance $\left(\mathrm{Y}_{1 \mathrm{i}}\right)$ obtained by participation in observations" and the "performance $\left(\mathrm{Y}_{0 \mathrm{i}}\right)$ not participating in the same observations"(Heckman et al., 1997). Therefore, the effect of a firm's technological innovation on employment can be defined as the difference between "a company that innovates technology" and "a company that does not innovate technology," which can be expressed as Equation (2). However, the individual companies used in this study are not all the same ones. In other words, what you can actually observe is $Y_{0 \mathrm{i}}$ or $Y_{1 \mathrm{i}}$, not $Y_{0 \mathrm{i}}$ and $Y_{1 \mathrm{i}}$. Therefore, the calculation of treatment effect has a problem of difference caused by whether the companies perform technological innovation activities or not. Heckman(1997) pointed out the problem of these observations and suggested the ATT (Average Treatment Effect on the Treated), which is a means to solve this problem. The ATT in Equation (5) implies the employment effect indicated by the company's technological innovation activities, and Equation (6) is the subdivision of the expected value according to the Equation (5), depending on whether the companies perform technological innovation activities or not.

(4) Treatment Effect $=\alpha_{i}=Y_{1 i}-Y_{0 i}$

(5) $\quad \mathrm{ATT}=\mathrm{E}\left(\mathrm{Y}_{1}-Y_{0} \mid \mathrm{D}=1\right)=\mathrm{E}\left(\mathrm{Y}_{1} \mid \mathrm{D}=1\right)-\mathrm{E}\left(Y_{0} \mid \mathrm{D}=1\right)$

(6) $\mathrm{E}\left(\mathrm{Y}_{1} \mid \mathrm{D}=1\right)-\mathrm{E}\left(Y_{0} \mid \mathrm{D}=1\right)=\mathrm{ATT}+\mathrm{E}\left(Y_{0} \mid \mathrm{D}=1\right)-\mathrm{E}\left(Y_{0} \mid \mathrm{D}=\mathbf{0}\right)$

However, an important problem may arise in Equation (6). This is because the treatment effect does not have the same probability distribution, so the sign may be different. In other words, of $\mathrm{E}\left(Y_{0} \mid \mathrm{D}=1\right)-\mathrm{E}\left(Y_{0} \mid \mathrm{D}=0\right)$ may not show the situation of $\mathrm{E}\left(Y_{0} \mid \mathrm{D}=1\right)-\mathrm{E}\left(Y_{0} \mid \mathrm{D}=0\right)=00^{3)}$ due to unexpected factors (e.g., corporate financial status, government intervention, company experience, etc.) other than the innovation activities by the company, and this leads to a problem of bias. Of course, you may get a pure ATT value from technological innovation activities. However, since the data used in this paper is obtained by a questionnaire rather than

3) For example, the issue whether the companies perform technological innovation activities can become $\mathrm{E}\left(Y_{0} \mid \mathrm{D}=1\right)>$ $E\left(Y_{0} \mid \mathrm{D}=0\right)$ by confounding factor. 
probabilistic data, the employment effect of firms' technological innovation can suffer from the problem of selection bias.

Estimation methods widely used to solve the bias problem include tool parameter estimation, Heckman's 2-step estimation, fixed effect estimation, etc. Each of these methods is excellent for bias control, but they also have their own shortcomings. When using cross-sectional data as in this study, it is difficult to find proper tool parameters. The fixed effect model should use lagged variables as independent variables. Using Heckman's 2-step estimation, it is difficult to find appropriate explanatory variables to distinguish the selection formula from the calculation formula.

Another way to control the selection bias of cross-sectional data is by using analysis based on matching. The basic framework of this method is to extract the covariates by finding common support between the companies that do or do not engage in technological innovation activities. Using this covariate extraction, you can estimate the employment effect by several matching methods with similar characteristics. Common support can be estimated through propensity scores. In this process, you can control and solve the problems of bias as well as dimension that can be caused by many common variables. ${ }^{4)}$ Therefore, the PSM method is suitable for this study because it compensates for the disadvantages of the data used. It also controls heterogeneity and disturbance factors between the two business groups.

\section{PSM (Propensity Score Matching)}

The estimation of PSM is made in two stages. The first step is to define the propensity scores. This implies the conditional probability of economic activities when a vector is given to observe the characteristics of firms engaged in innovation activities.

\section{(7) Propensity Score $=P(X)=\operatorname{Pr}\left(D_{i}=1 \mid X\right)=E\left(D_{i} \mid X\right)$}

In Equation (7), $\mathrm{X}$ is the individual feature vector of the treatment group that does innovation activities and the control group that does not perform innovation activities. $\mathrm{P}(\mathrm{X})$ is the probability of doing the innovation activities based on these characteristics. This propensity scores can be defined as the assumption ${ }^{5}$ of strong indifference between the two groups. The following Equations (8) and (9) summarize the hypotheses for defining the propensity scores.

\section{(8) Conditional Independent Assumption $=\left(\mathbf{Y}_{\mathbf{0 i}}, \mathbf{Y}_{\mathbf{1 i}}\right) \perp \mathbf{D}_{\mathbf{i}} \mid \mathbf{X}$}

(9) Common Support Assumption $=0<\operatorname{Pr}\left(D_{i}=1 \mid X\right)<1$

Equation (8) is Conditional Independent Assumption(CIA). It is assumed that when the covariate $X$ is given, the response variable $D_{i}$ is independent of $Y_{0 \mathrm{i}}$ and $Y_{1 \mathrm{i}}$, depending on the presence or absence of technological innovation activities. This means that any different factors that affect technological innovation activities can be controlled by individual variables, and that any unobserved characteristics do not affect employment effects.

Equation (9) indicates the Common Support Assumption(CSA). This assumes that the probability distributions used by the treatment group and the control group have the same common support (Rosenbaum and Rubin, 1983). Therefore, Propensity Score satisfies the above two assumptions, and if there are many variables that can measure the characteristics, then it is possible to calculate the bias-controlled employment effect by controlling them.

The second stage of PSM is to analyze the employment effects of firms through differences between groups that have similar propensity scores to the treatment group and are not 
engaged in technological innovation activities. In other words, when matching with the variables themselves, the magnitude of the effect can be examined by comparing the differences of the dimensional problems that occur using propensity scores that summarize the characteristics of the variables as one number. Equation (10) shows ATT, which is the effect of economic activities on employment through this estimation.

\section{(10) The effect of technological innovation on employment (ATT)$$
=\alpha=E\left(Y_{1 \mathrm{i}}-\mathrm{Y}_{0 \mathrm{i}} \mid \mathrm{D}_{\mathrm{i}}=1\right)
$$$$
=E\left\{E\left\{Y_{1 i}-Y_{0 i} \mid D_{i}=1, P(X)\right\}\right\}=E\left\{E\left\{Y_{1 i} \mid D_{i}=1, P(X)\right\}-E\left\{Y_{0 i}\left|D_{i}=0, P(X)\right| D=1\right\}\right\}
$$

PSM can be classified into Nearest Neighbor (NN) Matching, Radius Matching, Stratification Matching, and Kernel Matching5), depending on the method they use (Heckman et al, 1997).

Each matching method shows that there is a trade-off between bias and dispersion when evaluated based on the two factors, and there is no superior matching method in all cases. So we compare the estimation results from various matching methods (Becker, Sascha 0., 2002; Calendo \& Kopeining, 2008).

\section{DESCRIPTION OF MATERIALS AND VARIABLES}

\section{Data}

This study analyzed the financial statements of NICE Information Service and Science and Technology Policy Institute(STEPI)'s Korean Innovation Survey(KIS) conducted between 2012 to 2016 (manufacturing sector) to examine the employment effects of technological innovation activities on manufacturing companies. ${ }^{6}$ ) The KIS is the national statistics approved by the Korean government, which is surveyed every two or three years, based on the OECD Oslo Manual, and it is internationally comparable. The data makes it easy to analyze the performance of the innovation activities because it has systematized the current status and characteristics of the innovation activities by domestic companies. In addition, it is useful in examining the characteristics of companies because it is organized into business types (large, medium, and small enterprises) and industries.

It is important to remember that the KIS data is not panel data, but cross-section data. This means that it is impossible to carry out an analysis that takes time lag into account. As well, data that is more recent than 2012 has problems, as questions on corporate sales are organized categorically, and therefore the exact sales figures are unknown. Thus, each of the data adjusted the amount-related variables by matching the corporate IDs of the KIS to the financial statement from NICE Information Service. A considerable number of samples went missing in the process of adjusting this data. Accordingly, companies that did not respond to questions on the number of employees, sales figures, etc. were excluded. Also, companies with less than 10 and more than 50,000 full-time employees were excluded to avoid scenarios in which the estimations were determined by a few samples. For R\&D intensity, seven companies with extreme corporate sales and R\&D amounts were excluded, and companies established during the survey were also excluded.

Therefore, this study used the data of 5,757 corporations $(1,273$ large companies, 4,484 small $\&$ medium-sized companies) after missing data and extreme data were excluded to examine the employment effect of technological innovation by manufacturing companies.

\footnotetext{
5) The details of each matching method are explained in $<$ Appendix $1>$.

6) There were many values missing in the KIS data and there was a problem with a large number of the samples being smaller in the adjustment phase of cost-related variables. Therefore, the data of 2012 and 2014 were pooled for a more robust analysis.
} 
All concepts and terminologies used in the KIS are based on the Oslo Manual provided by the OECD. Accordingly, technological innovation was divided into product innovation and process innovation. Product innovation refers to the implementation of newly improved products or their launch in the market in terms of product characteristics, software, or user-friendliness or utility. Process innovation refers to making completely new methods through considerable improvements in the production process, logistics methods and support methods to help save production costs, logistics costs, and improve quality. In this study, a company is called a technological innovation company if either a product innovation or a process innovation was carried out, and the dummy variable was set as 1 or 0 depending on whether either was conducted. The employment increase rate was calculated according to the change in the number of full-time employees compared to the previous year. Furthermore, this study aimed to measure the employment effect of technological innovation according to the characteristics of each industry. To this end, using the industrial classification of the Bank of Korea, computer and office appliance manufacturing (30) and electronic parts, video, audio and communication manufacturing (32) were defined as ICT companies as per the $9^{\text {th }}$ Standard Industrial Classification, while other manufacturing businesses were categorized as non-ICT companies.

\section{Description of variables and basic statistics}

The propensity scores can be extrapolated from Probit or Logit analysis. These two methods can be used to obtain an estimate of the probability of a process assignment of observed variables in a given condition. In Probit analysis, the variables are assumed to be multivariate normal distributions. Logit analysis offers advantages in that it is more flexible in this assumption and more effective in bias control than Probit analysis (Rubin, 1979). Therefore, this study used logit analysis which is widely used.

In order to effectively estimate the propensity score matching, it is important to adjust the balance within the common support through the propensity score. ${ }^{7)}$ However, it is difficult to find mutually balanced variables in a limited area. In particular, due to issues such as a small sample size for missing data and the large amounts of binary data from the survey results, there were difficulties in finding variables with a proper balance. Thus, this study refers to a previous study (Hong, 2018) that analyzed technological innovation factors to organize a basic frame (Fig. 1) for the study, and comprehensively reviewed whether the two presumptions (conditional independency, presumption of common fields) with strong propensity scores from the given data were satisfied to set Equation (11).

FIGURE 1. Basic frame of the employment effect of technological innovation

\begin{tabular}{|c|c|c|c|}
\hline \multicolumn{3}{|c|}{ Propensity Score } & Matching \\
\hline \multicolumn{3}{|c|}{ Innovation } & Employment Effects \\
\hline Technological & Product & Process & \\
\hline \multirow{2}{*}{$\begin{array}{c}\text { Technological } \\
\text { innovation } \\
\text { investment factors }\end{array}$} & & & All companies \\
\hline & $\begin{array}{l}\text { Technological } \\
\text { innovation purrsuance } \\
\text { factors }\end{array}$ & Market factors & $\begin{array}{l}\text { Small si } \\
\text { medium-sized } \\
\text { companies } \\
\end{array}$ \\
\hline \multirow[t]{2}{*}{ - R\&ED Intensity } & 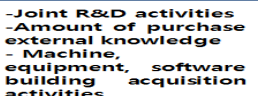 & $\begin{array}{l}\text { - Market control } \\
\text { by monopolistic } \\
\text { companies } \\
\text { Cuncertainty of } \\
\text { market demand }\end{array}$ & Non-1CT \\
\hline & & & $\begin{array}{l}\text { Stratification Nearest Neighbour, } \\
\text { Radius, Kernel Matching }\end{array}$ \\
\hline 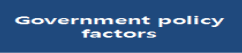 & Control variables & & L \\
\hline \multirow{2}{*}{$\begin{array}{l}\text { - Tax reduction for } \\
\text { technological } \\
\text { development } \\
\text { develoment }\end{array}$} & \multirow{2}{*}{$\begin{array}{l}\text { - Industry dummy } \\
\text { - Vears of Operation }\end{array}$} & & $\begin{array}{l}\text { Bias reduction test } \\
\text { Balancing test } \\
\end{array}$ \\
\hline & & & Imbalance test \\
\hline
\end{tabular}

7) Balancing means to block the similar segments of propensity scores between 0 and $100 \%$ to satisfy the common support between the companies that are engaged in innovation activities and those that are not engaged. If the balance between the blocks is not satisfied, then the common support cannot be calculated. 
(9) $\mathrm{Y}$ (Technological Innovation) = $\mathrm{f}$ (Technological Innovation investment factor, Technological Innovation pursuance factor, Market factor, Government policy factor, Control factor)

First, technological innovation is used as a dependent variable for calculating propensity scores. In the matching phase, the employment increase rate compared to the previous year is used as the dependent variable. For explanatory variables that affect technological innovation, the R\&D intensity, which is the R\&D investment ratio compared to sales, is used in the case of technological innovation investment factors. Such factors are the ultimate cause needed for companies to conduct technological innovation, and thus they are expected to have a positive $(+)$ relationship. Factors for pursuing technological innovation included corporate joint R\&D activities, amount of purchasing of external knowledge, and lack of technological innovation. Market factors are environmental factors that affect the implementation of technological innovation and use market control through monopolistic companies and uncertainty of market demand. Policy support in which the government becomes involved to respond to a market failure or system failure in technological innovation was also considered. Relevant factors include tax reductions granted to companies by the government. In addition, for exogenous variables affecting technological innovation, the characteristics (ICT companies, non-ICT companies) ${ }^{8)}$ of the industry that the company is part of and years of operation ${ }^{9}$ were reflected to control for their influence. <Table 1> shows basic statistics for examining the impact of technological innovation on employment.

<Table 1> Basic statistics of manufacturing companies

\begin{tabular}{|c|c|c|c|c|}
\hline & Variable & Description & Mean & Std. Err. \\
\hline \multirow{2}{*}{ Dependent variables } & $\begin{array}{l}\text { Technological innovation } \\
\text { (Propensity score dependent variable) }\end{array}$ & Dummy, binary variable & 0.365 & 0.421 \\
\hline & $\begin{array}{c}\text { Employment increase rate } \\
\text { (Matching dependent variable) }\end{array}$ & Ratio scale & 0.325 & 0.653 \\
\hline $\begin{array}{c}\text { Technological } \\
\text { innovation investment } \\
\text { factors }\end{array}$ & R\&D Intensity & Ratio scale & 5.017 & 7.025 \\
\hline \multirow{3}{*}{$\begin{array}{c}\text { Technological } \\
\text { innovation pursuance } \\
\text { factors }\end{array}$} & Joint R\&D activities & Dummy, binary variable & 0.311 & 0.518 \\
\hline & $\begin{array}{l}\text { Amount of purchase of external } \\
\text { knowledge }\end{array}$ & Ratio scale & 2.110 & 2.307 \\
\hline & $\begin{array}{l}\text { Machine, equipment, software and } \\
\text { building acquisition activities }\end{array}$ & Ratio scale & 1.829 & 1.535 \\
\hline \multirow{2}{*}{ Market factors } & $\begin{array}{l}\text { Market control by monopolistic } \\
\text { companies }\end{array}$ & Dummy, binary variable & 0.322 & 0.291 \\
\hline & Uncertainty of market demand & Dummy, binary variable & 0.387 & 0.425 \\
\hline $\begin{array}{l}\text { Government policy } \\
\text { factors }\end{array}$ & $\begin{array}{c}\text { Tax reduction for technological } \\
\text { development }\end{array}$ & Dummy, binary variable & 0.231 & 0.407 \\
\hline \multirow{3}{*}{ Control variables } & Industry dummy 1 & Dummy, binary variable & 0.423 & 0.495 \\
\hline & Industry dummy 2 & Dummy, binary variable & 0.251 & 0.388 \\
\hline & Years of operation & Ratio scale & 17.511 & 10.253 \\
\hline
\end{tabular}

Note: Data pooled from 2012 2016 KIS data. , Source: 2012 2016 Korean Innovation Survey, STEPI

8) Analysis on employment effect based on the size of the company utilized industry (ICT companies, non-ICT companies) dummy variables as control variables, while analysis of industry specific employment effects did not use them as control variables.

9) Years of operation was converted to and used as a ln. 


\section{ANALYTICAL RESULTS}

\section{Propensity score and common support}

The logit model was used to calculate the propensity scores according to the technological innovation of the manufacturing companies. The parameters estimated by the logit analysis are used in the computation of the propensity scores to find the common support of the sample used in the matching analysis. <Table $2>$ shows the results of the logit analysis of companies for the propensity score estimation according to technological innovation.

$<$ Table $2>$ The results of the logit analysis for the propensity score estimation

\begin{tabular}{|c|c|c|c|c|c|}
\hline Variable & $\begin{array}{c}\text { All } \\
\text { companies }\end{array}$ & $\begin{array}{c}\text { Major } \\
\text { companies }\end{array}$ & $\begin{array}{c}\text { Small \& } \\
\text { medium-sized } \\
\text { companies }\end{array}$ & ICT & Non-ICT \\
\hline & Coef. & Coef. & Coef. & Coef. & Coef. \\
\hline R\&D Intensity & $0.133^{* *}$ & $0.152^{* *}$ & $0.107^{*}$ & $0.190^{* *}$ & 0.054 \\
\hline Joint R\&D activities & $0.125^{*}$ & 0.105 & $1.186^{*}$ & $0.163^{*}$ & -0.016 \\
\hline $\begin{array}{l}\text { Amount of purchase of external } \\
\text { knowledge }\end{array}$ & $1.210^{* * *}$ & $0.852^{*}$ & $0.905^{* * *}$ & $1.875^{* * *}$ & $0.353^{*}$ \\
\hline $\begin{array}{l}\text { Machine, equipment, software } \\
\text { and building acquisition } \\
\text { activities }\end{array}$ & 0.502 & $0.863^{*}$ & $0.301^{*}$ & $0.393^{* *}$ & -0.051 \\
\hline $\begin{array}{l}\text { Market control by monopolistic } \\
\text { companies }\end{array}$ & $-0.052^{*}$ & -0.061 & $-0.093^{* *}$ & -0.015 & -0.194 \\
\hline Uncertainty of market demand & $-0.096^{*}$ & $-0.103^{*}$ & $-0.125^{* * *}$ & $-0.063^{*}$ & 0.132 \\
\hline $\begin{array}{c}\text { Tax reduction for technological } \\
\text { development }\end{array}$ & $0.406^{* * *}$ & $0.435^{* * *}$ & $0.297 * *$ & $0.493^{* * *}$ & $0.356^{* *}$ \\
\hline Years of operation & $0.059 * * *$ & $0.017^{* * *}$ & $0.016^{* *}$ & $0.032^{* * *}$ & $0.051^{* *}$ \\
\hline Industry dummy 1 & $0.117^{*}$ & $0.151^{* *}$ & -0.036 & & \\
\hline Industry dummy 2 & 0.315 & $0.575^{*}$ & 0.625 & & \\
\hline Constant & $0.921^{*}$ & $1.058^{* *}$ & $-0.553^{* *}$ & $1.227^{* *}$ & -0.181 \\
\hline Log likelihood & -270.215 & -82.354 & -195.325 & -134.251 & -258.384 \\
\hline Pseudo $\mathbf{R}^{2}$ & 0.084 & 0.092 & 0.075 & 0.106 & 0.058 \\
\hline Prob $>X^{2}$ & 135.05 & 120.21 & 137.25 & 201.07 & 76.57 \\
\hline
\end{tabular}

Note: *, ${ }^{* *}$ and ${ }^{* * *}$ mean that there is significance at the $1 \%, 5 \%$, and $10 \%$ levels, respectively.

The estimated coefficients show that overall, companies tended to participate in technological innovation activities more when there were more joint $R \& D$ activities and purchasing of external knowledge, and when government policies granted more tax benefits for technological development by companies. On the other hand, in terms of the market factors of companies, it was found that participation in technological innovation activities rose when uncertainty of demand decreased and the market control by monopolies was lower.

Signs of estimated coefficients showed mostly similar patterns for both large companies and small \& medium-sized enterprises. Large companies were found to be more likely to participate in technological innovation due to R\&D intensity and government policy factors compared to small and medium-sized companies. For technological activities, it was found that market factors were statistically more significant for small \& medium-sized companies than for large firms. An industrial characteristic of the companies was that ICT companies had more statistically significant variables than non-ICT companies. In particular, the coefficient value of the R\&D intensity and technological innovation pursuit factors was found to be higher for ICT companies compared to non-ICT companies. 
< Table 3> Common support calculated from the propensity scores

\begin{tabular}{|c|c|c|c|c|c|}
\hline & Before & After & \multirow{2}{*}{ Lost in \% } & \multicolumn{2}{|c|}{ Common Support } \\
\hline & \multicolumn{2}{|c|}{ Propensity Score } & & Min & Max \\
\hline All companies & 5,757 & 3,051 & 47.003 & 0.273 & 0.951 \\
\hline Major companies & 1,273 & 668 & 47.526 & 0.106 & 0.889 \\
\hline $\begin{array}{l}\text { Small \& medium- } \\
\text { sized companies }\end{array}$ & 4,484 & 2,186 & 51.249 & 0.322 & 0.985 \\
\hline ICT & 2,358 & 1,360 & 42.324 & 0.215 & 0.973 \\
\hline Non-ICT & 3,399 & 1,697 & 50.073 & 0.258 & 0.862 \\
\hline
\end{tabular}

$<$ Table 3> shows the result of the common support calculated by using the parameter estimates of the logit analysis derived from the propensity scores. As shown in the table, the sample size is reduced by the covariate characteristics in calculating the propensity scores, and the common support is larger than 0 and smaller than 1 , thus satisfying the common support assumption. The common support of each of these was calculated as 0.273 to 0.951 for all companies, 0.106 to 0.889 for major companies, 0.322 to 0.985 for small and medium-sized companies, 0.215 to 0.973 for ICT companies and 0.258 to 0.862 for non-ICT companies.

(Fig. 2) shows the propensity scores of this common support in a graph. The horizontal axis of the graph indicates propensity scores and the vertical axis indicates frequency. The upper part shows the treatment group that does technological innovation activities and the lower part shows the control group that does not do such activities. It can be concluded that the more similar the height of the two bars, the more similar the propensity scores of the two groups. As shown in (Fig. 2), it can be seen that the density functions of the propensity scores of the two groups overlap each other in the common support.

FIGURE 2. Propensity score graph of technological innovation by company

\begin{tabular}{|c|c|c|}
\hline All companies & Major companies & Small \& medium-sized companies \\
\hline & & \\
\hline ICT & & \\
\hline
\end{tabular}


To confirm whether the assumptions of conditional independence were met, the samples in the common support were divided into several blocks under the propensity score range. The blocks are divided into 9 overall companies, 5 large companies, 7 small and medium-sized companies, 6 ICT companies and 6 non-ICT companies. The average value of the propensity scores of the companies shows the difference between the two groups. As a result of the analysis, the average value of propensity scores did not differ between the two groups and satisfied the assumption of conditional independence. ${ }^{10)}$

\section{Employment effects of technological innovation in manufacturing firms}

We use the four PSMs mentioned above for the employment effects of technological innovation in manufacturing firms. Radius matching was performed with Caliper values of 0.1, 0.05, and 0.01.11) In the Kernel matching, the Epanechnikov kernel function is used, and the value of each bandwidth is 0.05 . NN matching was performed using one-to-one matching, which is generally used. Matching of Stratification and NN were analyzed by dividing into 9 overall companies, 5 large companies, 7 small and medium-sized companies, 6 ICT companies and 6 non-ICT companies, equal to the number of blocks obtained in the common support. The analysis of all matches performed 100 bootstrapping for $\mathrm{t}$-test.

The PSM can check how much bias has been reduced since each matching. $<$ Table $4>$ shows the percentage of bias reduction after the matching. 
$<$ Table 4> Bias reduction by PSM

\begin{tabular}{|c|c|c|}
\hline & Matching & Bias reduction after matching (\%) \\
\hline \multirow{6}{*}{ All companies } & Stratification & $-59.1(\%)$ \\
\hline & Nearest Neighbour (NN) & $-70.9(\%)$ \\
\hline & Radius (caliper 0.1) & $-65.3(\%)$ \\
\hline & Radius (caliper 0.05) & $-66.1(\%)$ \\
\hline & Radius (caliper 0.01) & $-66.9(\%)$ \\
\hline & Kernel & $-65.5(\%)$ \\
\hline \multirow{6}{*}{ Major companies } & Stratification & $-48.6(\%)$ \\
\hline & Nearest Neighbour (NN) & $-57.2(\%)$ \\
\hline & Radius (caliper 0.1) & $-49.8(\%)$ \\
\hline & Radius (caliper 0.05) & $-40.9(\%)$ \\
\hline & Radius (caliper 0.01) & $-41.2(\%)$ \\
\hline & Kernel & $-50.5(\%)$ \\
\hline \multirow{6}{*}{$\begin{array}{l}\text { Small \& medium } \\
\text { companies }\end{array}$} & Stratification & $-57.9(\%)$ \\
\hline & Nearest Neighbour (NN) & $-63.1(\%)$ \\
\hline & Radius (caliper 0.1) & $-59.0(\%)$ \\
\hline & Radius (caliper 0.05) & $-60.3(\%)$ \\
\hline & Radius (caliper 0.01) & $-61.6(\%)$ \\
\hline & Kernel & $-59.0(\%)$ \\
\hline \multirow{6}{*}{ ICT } & Stratification & $-50.1(\%)$ \\
\hline & Nearest Neighbour (NN) & $-59.1(\%)$ \\
\hline & Radius (caliper 0.1) & $-55.5(\%)$ \\
\hline & Radius (caliper 0.05) & $-56.2(\%)$ \\
\hline & Radius (caliper 0.01) & $-58.0(\%)$ \\
\hline & Kernel & $-56.9(\%)$ \\
\hline \multirow{6}{*}{ Non-ICT } & Stratification & $-59.2(\%)$ \\
\hline & Nearest Neighbour (NN) & $-68.1(\%)$ \\
\hline & Radius (caliper 0.1) & $-60.2(\%)$ \\
\hline & Radius (caliper 0.05) & $-61.3(\%)$ \\
\hline & Radius (caliper 0.01) & $-62.2(\%)$ \\
\hline & Kernel & $-60.9(\%)$ \\
\hline
\end{tabular}

As shown in $<$ Table $4>$, the bias was reduced for all matchings. ${ }^{12)}$ In particular, the bias of small and medium-sized companies was reduced more than that of major companies, and the bias of non-ICT companies was reduced more than ICT companies. The difference in the bias reduction is caused by the change in the number of samples when the common support is calculated according to propensity score. The proportion of reduction of each bias varied according to the type of matching. In this case, the NN matching made the most of the bias reduction, followed by radius, kernel, and Stratification. In the case of Radius matching, the lower the caliper was set, the higher the rate of bias reduction was measured.

12) The matching method can result in an effective estimation, depending on how much heterogeneity is controlled between the variables of the two comparative groups. That is, the bias after matching should be controlled. In this study, the bias reduction was tested for the effectiveness of this matching. As a result of the test, the groups were compared with the average of the variables before the matching and after the matching, and the bias reduction was confirmed in all the variables. Also, all the $\mathrm{P}$ values before the matching were low, but after the matching, they increased in all the variables. This indicates that the variables in the two groups are no different from each other. Therefore, the results of this study are omitted in this paper. 
<Table 5> Employment effects of technological innovation in manufacturing firms: PSM

\begin{tabular}{|c|c|c|c|c|c|c|}
\hline & Matching & $\begin{array}{c}\text { Imbalance } \\
\text { test }\end{array}$ & $\begin{array}{l}\text { Technological } \\
\text { Innovation }\end{array}$ & $\begin{array}{c}\text { Non- } \\
\text { technological } \\
\text { Innovation }\end{array}$ & ATT & Std. Err. \\
\hline \multirow{6}{*}{$\begin{array}{c}\text { All } \\
\text { companies }\end{array}$} & Stratification & 0.115 & 1086 & 1,115 & $0.151^{*}$ & 0.201 \\
\hline & $\begin{array}{l}\text { Nearest Neighbour } \\
\text { (NN) }\end{array}$ & 0.087 & 952 & 886 & $0.175^{* *}$ & 0.184 \\
\hline & Radius(caliper 0.1) & 0.092 & 1,053 & 1,020 & $0.102^{*}$ & 0.147 \\
\hline & Radius(caliper 0.05) & 0.090 & 1,042 & 1,016 & $0.115^{*}$ & 0.161 \\
\hline & Radius(caliper 0.01) & 0.083 & 1,020 & 985 & $0.131^{* *}$ & 0.170 \\
\hline & Kernel & 0.095 & 1,015 & 912 & $0.166^{*}$ & 0.182 \\
\hline \multirow{6}{*}{$\begin{array}{c}\text { Major } \\
\text { companies }\end{array}$} & Stratification & 0.097 & 301 & 332 & $0.170^{*}$ & 0.166 \\
\hline & $\begin{array}{l}\text { Nearest Neighbour } \\
\text { (NN) }\end{array}$ & 0.072 & 285 & 293 & $0.189^{* * *}$ & 0.143 \\
\hline & Radius(caliper 0.1) & 0.083 & 301 & 325 & $0.103^{*}$ & 0.117 \\
\hline & Radius(caliper 0.05) & 0.076 & 295 & 317 & $0.116^{* *}$ & 0.121 \\
\hline & Radius(caliper 0.01) & 0.070 & 293 & 312 & $0.125^{* *}$ & 0.133 \\
\hline & Kernel & 0.080 & 297 & 315 & $0.114^{* *}$ & 0.108 \\
\hline \multirow{6}{*}{$\begin{array}{c}\text { Small \& } \\
\text { medium } \\
\text { companies }\end{array}$} & Stratification & 0.128 & 887 & 952 & $0.095^{*}$ & 0.198 \\
\hline & $\begin{array}{l}\text { Nearest Neighbour } \\
\text { (NN) }\end{array}$ & 0.086 & 863 & 841 & $0.098^{* *}$ & 0.139 \\
\hline & Radius(caliper 0.1) & 0.107 & 896 & 921 & 0.090 & 0.138 \\
\hline & Radius(caliper 0.05) & 0.101 & 885 & 919 & $0.097^{*}$ & 0.125 \\
\hline & Radius(caliper 0.01) & 0.095 & 882 & 910 & $0.101^{* *}$ & 0.117 \\
\hline & Kernel & 0.103 & 885 & 908 & $0.094^{*}$ & 0.108 \\
\hline \multirow{6}{*}{ ICT } & Stratification & 0.112 & 651 & 698 & $0.047^{*}$ & 0.044 \\
\hline & $\begin{array}{l}\text { Nearest Neighbour } \\
\text { (NN) }\end{array}$ & 0.078 & 632 & 640 & $0.052^{* *}$ & 0.187 \\
\hline & Radius(caliper 0.1) & 0.094 & 649 & 682 & 0.010 & 0.160 \\
\hline & Radius(caliper 0.05) & 0.086 & 645 & 672 & 0.002 & 0.151 \\
\hline & Radius(caliper 0.01) & 0.079 & 643 & 669 & 0.019 & 0.149 \\
\hline & Kernel & 0.097 & 647 & 683 & $0.036^{*}$ & 0.163 \\
\hline \multirow{6}{*}{ Non-ICT } & Stratification & 0.131 & 795 & 872 & 0.096 & 0.189 \\
\hline & $\begin{array}{l}\text { Nearest Neighbour } \\
\text { (NN) }\end{array}$ & 0.082 & 727 & 803 & $0.127^{* *}$ & 0.156 \\
\hline & Radius(caliper 0.1) & 0.106 & 755 & 854 & $0.098^{*}$ & 0.142 \\
\hline & Radius(caliper 0.05) & 0.098 & 751 & 842 & $0.102^{*}$ & 0.138 \\
\hline & Radius(caliper 0.01) & 0.090 & 749 & 836 & $0.111^{* *}$ & 0.134 \\
\hline & Kernel & 0.107 & 756 & 836 & $0.103^{*}$ & 0.137 \\
\hline
\end{tabular}

Note: ${ }^{* *}$ and ${ }^{* * *}$ mean that there is significant at $1 \%, 5 \%$, and $10 \%$ levels, respectively.

$<$ Table 5> Shows the ATT, which is the employment effect according to the technological innovation activities by the manufacturing companies. This shows the average difference between the treatment group and the control group belonging to the common support for each matching. The sample used for the matching showed a slight difference, depending on each method. Overall companies are divided into 952 to 1,053 treatment groups and 886 to 1,115 control groups for each analysis. Major companies are divided into 285 to 301 treatment groups and 293 to 332 control groups. Small and medium-sized companies are divided into 863 to 887 treatment groups and 841 to 952 control groups. ICT companies are divided into 632 to 651 treatment groups and 640 to 698 control groups. And non-ICT companies are divided 727 to 795 treatment groups and 803 to 872 control groups. 
For the qualitative evaluation of the matching, an imbalance test was performed for each analysis. The imbalance test confirms the similarity of the variables between the treatment group and the control group. ${ }^{13}$ ) The imbalance test result of each matching showed similar patterns regardless of the company size or business type. As a result, the NN and Radius matching showed relatively low imbalance, and Stratification and Kernel matching showed high imbalance. Therefore, when these two analyses match, it can be interpreted that the similarity of individual characteristics between the two groups is lower than other matching.

The employment effects of the firms' innovation activities based on the results of the ATT can be interpreted as a positive $(+)$ sign in most ATT values, indicating that technological innovation produces an increase in employment. Comparing the ATT by company size, the overall group showed an increase in the number of employees as follows: 0.151 in Stratification, 0.175 in NN, 0.102 to 0.131 in Radius, and 0.166 in Kernel. In addition, major companies showed employment increase by 0.170 in Stratification, 0.189 in NN, 0.103 to 0.125 in Radius, and 0.114 in Kernel, and the figures in the case of small and medium-sized companies were 0.095 in Stratification, 0.98 in NN, 0.090 to 0.101 in Radius, and 0.094 in Kernel. We can see the severe difference in the employment effects between small companies and major companies. This is interpreted as the difference in the number of the employees according to the size of the enterprises. The employment effect due to technological innovation was found to be higher in non-ICT companies than in ICT companies in all matching results. As pointed out by Moon and Jeon (2008), this is judged to result from the fact that in non-ICT companies with lower technological levels, there is a higher likeliness of increased productivity, which boosts labor demand, through the development of new products due to non-price elements such as design and materials, rather than price drops and increased demand. Furthermore, if production technologies of existing products and production technologies needed to produce new products are completely different or have disparities in technological levels, the efficiency of new product production can become relatively lower. The unique part in the matching method was that the lower the caliper value in Radius, the more the ATT value increases. This suggests that as the caliper decreases, the similarity in the characteristics between the treatment group and the control group becomes closer, increasing the ATT levels. For this reason, the imbalance of the two groups decreases.

In addition, this study further compares the employment effects of product innovation and process innovation on manufacturing firms. The results are show in <Appendix $2>$ and $<$ Appendix 3>. The results show that product innovation had a positive $(+)$ effect on employment for all companies. In contrast, process innovation had a negative (-) effect on employment for matching results (all companies, small \& medium companies, ICT companies, non-ICT companies), with the exception of large companies. The previous study of Moon and Jeon (2008) showed that the employment effect of process innovation was not statistically significant, but in this study most of the results proved to be significant. In particular, the employment reduction effect of process innovation was found to be greater for ICT companies compared to non-ICT companies. This indicates that the increase of production efficiency through process innovation was aimed at reducing employment. In other words, the increase of production efficiency leads to a drop in product prices, which in turn increases product demand. However, compared to the resulting compensation effect $(+)$ in which labor demand increases, the bigger labor expulsion effect $(-)$ from the more efficient process offsets the employment increase effect.

13) Iacus, Kings, and Porro (2010) evaluated the reliability of the results of the matching through an imbalance test. The lower the number, the higher the similarity of individual characteristics between the two groups. 


\section{CONCLUSION AND IMPLICATIONS}

In this study, we analyzed the size of firms to measure the employment effects of technological innovation. The analysis used PSM as a measure to control the problem of bias that could arise from the characteristics of the cross-sectional data. According to the results of the analysis, participation of manufacturing companies in technological innovation activities has a positive $(+)$ effect(ATT) on employment, and large companies showed a stronger positive (+) effect compared to small and medium-sized companies, while non-ICT companies had a stronger positive $(+)$ effect than ICT companies. In addition, while product innovation had a positive $(+)$ effect on employment in all areas, process innovation had a negative (-) effect in all matching results, with the exception of large companies.

The implications of employment effects created by technological innovation are as follows:

First, manufacturing companies showed higher participation in technological innovation activities when there were higher technological innovation investment factors and driving factors, stronger government policy support, and when the uncertainty of market demand and market control by monopolies were lower.

Second, it is confirmed that major companies showed greater effects of technological innovation activities on employment than small companies.

Third, product innovation had a positive (+) effect on employment, but process innovation had a negative ( - ) effect, with large companies being the exception. This shows that the aim of increased production efficiency was to lower labor demand. Thus to improve the efficiency of government R\&D policies, of the technological innovations, support for developing new products or improving existing ones should be expanded, since product innovation has a positive impact on employment.

For today's venture companies and 'innobiz' companies, as there are many qualitative elements included in evaluating the technological innovation capacities of companies, it has been suggested that the scope of target for relevant policies is ambiguous. Based on the results of this study, which indicate that technological innovation and product innovation have positive impacts on employment while process innovation has negative impacts, it was possible to provide objective and clear standards for policy targets. As the launching of new products has a positive effect on employment, the focus should be placed on policies that support the market entry and commercialization of new products. In addition, based on the research finding that technological innovation has a bigger employment effect for large companies than for small and medium-sized companies, this study implies the necessity of redirecting policy benefits more towards small and medium-sized companies than large companies.

Finally, one of the limitations of this study that should be complemented is the incompleteness of the sample data. The Korean Innovation Survey used in this study is meaningful in that it systematically summarizes all the information related to the innovation of the company. However, as this is survey data, there are many missing values in the data, and a considerable number of samples were downsized while adjusting amount-related variables and extreme values. In addition, since the data is panel data, not cross-sectional data, there are limitations in estimating dynamic employment effects because companies subject to the survey are different every year.

This study is meaningful in that it examines the effects of technological innovation activities by Korean manufacturing companies on employment by company size and business type, and 
used more rigorous analysis methods than previous studies to control selection bias. However, there is a limit in that the propensity score equation of the innovation activities does not consider various factors that affect the innovation of the companies. This is left as a future research project.

\section{APPENDIX 1}

PSM can be classified into Nearest Neighbor (NN), Radius, Stratification, Kernel, and Matching, depending on the method they use (Heckman et al, 1997). First, to do the NN matching, randomly arrange two groups: technologically innovative companies and non-innovative companies. Then, select non-innovative companies that have the closest propensity scores with the innovative companies. If we express this as a formula, let $\mathrm{T}$ be the group of companies that performs technological innovation activities, and $\mathrm{C}$ be the companies that do not perform innovation activities. Their employment effects can be expressed as $Y_{i}^{T}$ and $Y_{j}^{C}$, respectively. In addition, if $\mathrm{C}(\mathrm{i})$ is the $\mathrm{X}$-th firm that does not carry out technological innovation, and has a propensity score of $\mathrm{P}, \mathrm{NN}$ matching can extract it as a sample as shown in Equation (1).

\section{(1) $C(i)=\min _{j}\left\|p_{i}-p_{j}\right\|$}

Radius matching extracts the comparative group in a manner similar to NN matching. However, there is a difference in that the group of firms that are not engaged in the innovation activities with a propensity score within a certain radius $(r)$ is regarded as a comparative group. Equation (2) represents the extraction of the comparative group in the Radius matching.

$$
\text { (2) } \mathbf{C}(\mathbf{i})=\left\{\mathbf{p}_{\mathbf{j}} \mid\left\|\mathbf{p}_{\mathbf{i}}-\mathbf{p}_{\mathbf{j}}\right\|<C\right\}
$$

The employment effect of the NN and Radius matching is calculated as the mean value of the difference in the number of employees between the innovative group and the non-innovative group, which can be used to estimate ATT in the same way as Equation (3).

$$
\text { (3) } \quad \alpha=\frac{1}{\mathbf{N}^{\mathbf{T}}} \sum_{\mathbf{i} \in \mathbf{T}}\left\{\mathbf{Y}_{\mathbf{i}}^{\mathbf{T}}-\sum_{\mathbf{j} \in \mathbf{C}(\mathbf{i})} \mathbf{w}_{\mathbf{i j}} \mathbf{Y}_{\mathbf{j}}^{\mathbf{C}}\right\}==\frac{1}{\mathbf{N}^{\mathbf{T}}}\left\{\sum_{\mathbf{i} \in \mathbf{T}} \mathbf{Y}_{\mathbf{i}}^{\mathbf{T}}-\sum_{\mathbf{i} \in \mathbf{T}} \sum_{\mathbf{j} \in \mathbf{C}(\mathbf{i})} \mathbf{w}_{\mathbf{i j}} \mathbf{Y}_{\mathbf{j}}^{\mathbf{C}}\right\}
$$

In Equation (3), $\mathrm{N}^{\mathrm{T}}$ is the number of firms in a group of technologically innovative firms, and $\mathrm{N}_{\mathrm{i}}^{\mathrm{C}}$ is the number of non-innovative firms in pairs with $\mathrm{i} \in \mathrm{T}$. Also, $\mathrm{w}_{\mathrm{ij}}$ is a weighting value, and if it is $\mathrm{j} \in \mathrm{C}(\mathrm{i})$, it has a value of $\mathrm{w}_{\mathrm{ij}}=\frac{1}{\mathrm{~N}_{\mathrm{i}}^{\mathrm{C}}}$; otherwise it is $\mathrm{w}_{\mathrm{ij}}=0$. The dispersion of the employment effect of the NN and Radius matching can be expressed by the following Equation (4). In the case of the NN matching, there is a disadvantage in that the number of samples is reduced when estimating the employment effect because the closest object is selected as the comparative group.

(4) $\operatorname{Var}(\boldsymbol{\alpha})=\frac{1}{\left(\mathbf{N}^{\mathrm{T}}\right)^{2}}\left\{\sum_{\mathbf{i} \in \mathbf{r}} \operatorname{Var}\left(\mathbf{Y}_{\mathbf{i}}^{\mathbf{T}}\right)+\sum_{\mathbf{j} \in \mathbf{C}(\mathbf{i})}\left(\mathbf{w}_{\mathbf{i j}}\right)^{2} \operatorname{Var}\left(\mathbf{Y}_{\mathbf{j}}^{\mathbf{C}}\right)\right\}$ 
Kernel and Stratification matching is a way to overcome the disadvantages of the NN matching. Kernel matching is characterized by focusing on the comparative group as a whole to comprehend the effect. In other words, each firm that performs the innovation activities compares with the weighted average value of all firms in the non-innovative enterprise group, and a high weight is applied to good matching. The employment effect by Kernel matching is estimated by Equation (5).

(5) $\quad \alpha=\frac{1}{N^{T}} \sum_{i \in T}\left\{Y_{i}^{T}-\frac{\sum_{j \in C} Y_{j}^{C} G\left(\frac{p_{j}-p_{i}}{b_{n}}\right)}{\sum_{k \in C} G\left(\frac{p_{k}-p_{i}}{b_{n}}\right)}\right\}$

In Equation (5), G (•) is the Kernel function, and $b_{n}$ in the function is the bandwidth. The standard deviation of the employment effect through the Kernel matching can be calculated through bootstrapping.

Stratification matching is a method of estimating the characteristics of business groups according to the presence or absence of technological innovation activities identified by the propensity scores by grouping them into several blocks within a common support between the two groups. Each of these blocks can show the employment effects of innovation activities by firms through averaged work. The estimation of the employment effect through Stratification matching is shown in Equation (6).

(6) $\boldsymbol{\alpha}_{\mathrm{k}}=\frac{\sum_{\mathrm{i} \in I(\mathrm{k})} \mathbf{Y}_{\mathrm{i}}^{\mathrm{T}}}{\mathbf{N}_{\mathrm{k}}^{\mathrm{T}}}-\frac{\sum_{\mathrm{j} \in I(\mathrm{k})} \mathbf{Y}_{\mathrm{j}}^{\mathrm{C}}}{\mathbf{N}_{\mathrm{k}}^{\mathrm{C}}}$

In Equation (6), I(k) refers to the companies belonging to the $\mathrm{k}$-th group, $\mathrm{N}_{\mathrm{k}}^{\mathrm{T}}$ and $\mathrm{N}_{\mathrm{k}}^{\mathrm{C}}$ are the number of firms in the treatment group that perform technological innovation activities and the number of firms in the control group that do not perform such activities. The employment effect of Stratification matching by technological innovation of the company can be expressed by Equations (7) and (8). In the equation, $\mathrm{K}$ denotes the number of blocks, and $\mathrm{D}_{\mathrm{i}}$ denotes a dummy variable having a weight value of 0 and 1 .

(7) $\alpha=\sum_{b=1}^{K} \alpha_{b} \frac{\sum_{i \in I(k)} D_{i}}{\sum_{\forall i} D_{i}}$

(8) $\operatorname{Var}(\alpha)=\frac{1}{N^{T}}\left\{\operatorname{Var}\left(\mathbf{Y}_{\mathbf{i}}^{T}\right)+\sum_{\mathbf{j} \in I(b)} \frac{N_{k}^{T}}{N^{T}} \frac{N_{k}^{T}}{N_{k}^{C}} \operatorname{Var}\left(Y_{j}^{C}\right)\right\}$ 
APPENDIX 2

TABLE A1. Employment effects of product innovation in manufacturing firms: PSM

\begin{tabular}{|c|c|c|c|c|c|c|}
\hline & Matching & $\begin{array}{c}\text { Imbalance } \\
\text { test }\end{array}$ & $\begin{array}{c}\text { Product } \\
\text { Innovation }\end{array}$ & $\begin{array}{c}\text { Non- } \\
\text { Product } \\
\text { Innovation }\end{array}$ & ATT & Std. Err. \\
\hline \multirow{6}{*}{$\begin{array}{c}\text { All } \\
\text { companies }\end{array}$} & Stratification & 0.145 & 997 & 1103 & $0.167^{*}$ & 0.159 \\
\hline & Nearest Neighbour (NN) & 0.120 & 985 & 1002 & $0.181^{* *}$ & 0.174 \\
\hline & Radius(caliper 0.1) & 0.060 & 976 & 986 & $0.113^{* *}$ & 0.131 \\
\hline & Radius(caliper 0.05) & 0.057 & 960 & 975 & $0.120^{* *}$ & 0.128 \\
\hline & Radius(caliper 0.01) & 0.031 & 952 & 968 & $0.127^{* *}$ & 0.109 \\
\hline & Kernel & 0.113 & 985 & 921 & $0.170^{* *}$ & 0.181 \\
\hline \multirow{6}{*}{$\begin{array}{c}\text { Major } \\
\text { companies }\end{array}$} & Stratification & 0.138 & 257 & 315 & $0.181^{*}$ & 0.192 \\
\hline & Nearest Neighbour (NN) & 0.127 & 238 & 302 & $0.190^{* *}$ & 0.209 \\
\hline & Radius(caliper 0.1) & 0.115 & 250 & 312 & $0.120^{*}$ & 0.138 \\
\hline & Radius(caliper 0.05) & 0.102 & 241 & 307 & $0.128^{*}$ & 0.142 \\
\hline & Radius(caliper 0.01) & 0.100 & 229 & 290 & $0.132^{*}$ & 0.152 \\
\hline & Kernel & 0.129 & 245 & 310 & $0.155^{*}$ & 0.175 \\
\hline \multirow{6}{*}{$\begin{array}{c}\text { Small \& } \\
\text { medium } \\
\text { companies }\end{array}$} & Stratification & 0.121 & 821 & 889 & $0.117^{*}$ & 0.149 \\
\hline & Nearest Neighbour (NN) & 0.116 & 803 & 877 & 0.120 & 0.110 \\
\hline & Radius(caliper 0.1) & 0.105 & 795 & 870 & $0.115^{* *}$ & 0.133 \\
\hline & Radius(caliper 0.05) & 0.097 & 788 & 855 & $0.128^{* *}$ & 0.142 \\
\hline & Radius(caliper 0.01) & 0.092 & 779 & 839 & $0.135^{* *}$ & 0.151 \\
\hline & Kernel & 0.090 & 812 & 887 & $0.129^{* * *}$ & 0.162 \\
\hline \multirow{6}{*}{ ICT } & Stratification & 0.098 & 559 & 628 & $0.062^{*}$ & 0.113 \\
\hline & Nearest Neighbour (NN) & 0.092 & 536 & 604 & 0.081 & 0.102 \\
\hline & Radius(caliper 0.1) & 0.090 & 541 & 581 & $0.032^{*}$ & 0.052 \\
\hline & Radius(caliper 0.05) & 0.081 & 538 & 573 & $0.041^{* *}$ & 0.056 \\
\hline & Radius(caliper 0.01) & 0.072 & 510 & 546 & $0.058^{* *}$ & 0.065 \\
\hline & Kernel & 0.101 & 542 & 610 & 0.076 & 0.105 \\
\hline \multirow{6}{*}{ Non-ICT } & Stratification & 0.120 & 762 & 808 & $0.103^{*}$ & 0.127 \\
\hline & Nearest Neighbour (NN) & 0.099 & 738 & 795 & $0.126^{* *}$ & 0.142 \\
\hline & Radius(caliper 0.1) & 0.095 & 705 & 769 & $0.101^{* *}$ & 0.105 \\
\hline & Radius(caliper 0.05) & 0.084 & 698 & 715 & $0.115^{* *}$ & 0.126 \\
\hline & Radius(caliper 0.01) & 0.072 & 692 & 702 & $0.129^{* * *}$ & 0.139 \\
\hline & Kernel & 0.113 & 746 & 801 & 0.120 & 0.150 \\
\hline
\end{tabular}

Note: ${ }^{*}{ }^{* *}$ and ${ }^{* * *}$ mean that there is significance at the $1 \%, 5 \%$, and $10 \%$ levels, respectively 


\section{APPENDIX 3}

TABLE A2. Employment effects of process innovation in manufacturing firms: PSM

\begin{tabular}{|c|c|c|c|c|c|c|}
\hline & Matching & $\begin{array}{c}\text { Imbalance } \\
\text { test }\end{array}$ & $\begin{array}{c}\text { Process } \\
\text { Innovation }\end{array}$ & $\begin{array}{c}\text { Non- } \\
\text { Process } \\
\text { Innovation }\end{array}$ & ATT & Std. Err.. \\
\hline \multirow{6}{*}{$\begin{array}{c}\text { All } \\
\text { companies }\end{array}$} & Stratification & 0.231 & 610 & 825 & $-0.023^{* * *}$ & 0.052 \\
\hline & Nearest Neighbour (NN) & 0.210 & 585 & 821 & $-0.018^{* * *}$ & 0.041 \\
\hline & Radius(caliper 0.1) & 0.206 & 592 & 803 & $0.001^{*}$ & 0.032 \\
\hline & Radius(caliper 0.05) & 0.195 & 583 & 790 & $-0.010^{*}$ & 0.028 \\
\hline & Radius(caliper 0.01) & 0.181 & 575 & 776 & $-0.020^{*}$ & 0.020 \\
\hline & Kernel & 0.223 & 602 & 821 & $-0.017^{* *}$ & 0.046 \\
\hline \multirow{6}{*}{$\begin{array}{c}\text { Major } \\
\text { companies }\end{array}$} & Stratification & 0.115 & 101 & 179 & 0.017 & 0.048 \\
\hline & Nearest Neighbour (NN) & 0.107 & 101 & 162 & 0.026 & 0.051 \\
\hline & Radius(caliper 0.1) & 0.096 & 98 & 148 & $0.010^{*}$ & 0.038 \\
\hline & Radius(caliper 0.05) & 0.088 & 91 & 130 & $0.005^{*}$ & 0.030 \\
\hline & Radius(caliper 0.01) & 0.080 & 89 & 111 & $-0.003^{* *}$ & 0.015 \\
\hline & Kernel & 0.105 & 100 & 162 & 0.015 & 0.035 \\
\hline \multirow{6}{*}{$\begin{array}{c}\text { Small \& } \\
\text { medium } \\
\text { companies }\end{array}$} & Stratification & 0.132 & 327 & 413 & $-0.055^{* * *}$ & 0.081 \\
\hline & Nearest Neighbour (NN) & 0.120 & 321 & 402 & $-0.062^{* * *}$ & 0.079 \\
\hline & Radius(caliper 0.1) & 0.115 & 315 & 396 & -0.042 & 0.076 \\
\hline & Radius(caliper 0.05) & 0.106 & 309 & 375 & $-0.048^{*}$ & 0.070 \\
\hline & Radius(caliper 0.01) & 0.098 & 295 & 353 & $-0.051^{*}$ & 0.065 \\
\hline & Kernel & 0.125 & 322 & 399 & $-0.068^{* *}$ & 0.080 \\
\hline \multirow{6}{*}{ ICT } & Stratification & 0.121 & 204 & 310 & $-0.016^{* *}$ & 0.018 \\
\hline & Nearest Neighbour (NN) & 0.113 & 195 & 275 & $-0.021^{*}$ & 0.030 \\
\hline & Radius(caliper 0.1) & 0.107 & 192 & 252 & -0.006 & 0.015 \\
\hline & Radius(caliper 0.05) & 0.095 & 181 & 245 & $-0.012^{*}$ & 0.012 \\
\hline & Radius(caliper 0.01) & 0.089 & 175 & 233 & $-0.018^{*}$ & 0.010 \\
\hline & Kernel & 0.106 & 201 & 271 & $-0.024^{* *}$ & 0.027 \\
\hline \multirow{6}{*}{ Non-ICT } & Stratification & 0.098 & 255 & 306 & $-0.095^{*}$ & 0.108 \\
\hline & Nearest Neighbour (NN) & 0.095 & 253 & 290 & $-0.108^{* *}$ & 0.098 \\
\hline & Radius(caliper 0.1) & 0.092 & 243 & 292 & $-0.105^{* *}$ & 0.085 \\
\hline & Radius(caliper 0.05) & 0.089 & 230 & 271 & $-0.112^{* *}$ & 0.082 \\
\hline & Radius(caliper 0.01) & 0.082 & 227 & 260 & $-0.121^{* *}$ & 0.079 \\
\hline & Kernel & 0.097 & 253 & 301 & $-0.110^{*}$ & 0.102 \\
\hline
\end{tabular}

Note: ${ }^{*}{ }^{* *}$ and ${ }^{* * *}$ mean that there is significance at the $1 \%, 5 \%$, and $10 \%$ levels, respectively 


\section{References}

Aghion P. and Howitt, P. (1994), Growth and Unemployment, Review of Economic Studies, 61(3), pp. 477-494.

Becker, Sascha O. (2002),Estimation of Average Treatment Effects Based on Propensity Scores, The STATA Journal, 3(3)

Blundell, R. and Costa-Dias, M. (2009), Alternative Approaches to Evaluation in Empirical Microeconomics, Journal of Human Resources, 44(3), pp. 565-640.

Bae, Yongho, Ha, Taejeong, Kim, Byungwoo and Chang Byungyeol (2006), Direction of Innovation Policy for Growth and Employment Promotion, STEPI Policy Research, No. 05.

Caballero, R. J. and Hammour M. L., Jobless Growth (1997), Appropriability, Factor Substitution, and Unemployment, NBER Working Paper No. 6221.

Caliendo M, and S. Kopeining (2008), Some Practical Guidance for the Implementation of

Propensity Score Matching", Journal of Economics Surveys, 22(1), pp 31-72.

Dehejia, Rajeev H. and Sadek Wahba (1999), Causal Effects in Nonexperimental Stuies: Reevaluating the Evaluation of Training programs, Journal of Economic Review, 85(4), pp.923-937.

Evangelista, R. and Savona, M. (2003), Innovation, employment and skills in services. Firm and sectoral evidence, Structural Change and Economic Dynamics, 14(4), pp. 449-474.

Evangelista, R., and Vezzani, A. (2011), The impact of technological and organizational innovations on employment in European firms, Industrial and Corporate Change, 21(4), pp. 871-899.

Harrison, R. aumandreu, Mairesse and Peters, B. (2005), Does innovation stimulate employment? A firm-level analysis using comparable micro data on four European countries, MPRA Paper 1245, University Library of Munich, Germany.

Heckman, J.J.and Ichmura H., Todd P. E. (1997), Matching as a Econometric Evaluation Estimator: Evidence from Evaluating a Job Training Programme, Review of Metric Study, pp.605-654

Ha, Taejeong (2005), An Empirical Study on Technological Innovation and Structural Unemployment, STEPI Policy Research, No. 03.

Hong, Jiseung (2015), An Analysis of the Factors Affecting the Performance of Technological Innovation, KISTI Iacus, S., King G., and Porro, G. (2012), Multivariate Matching Methods That Are Monotonic Imblance Bounding”, Journal of the American Statistical Association, 106(493), pp. 345-346.

Jaumandreu, J. (2003), Does innovation spur employment? A Firm-level analysis using Spanish CIS data, paper prepared for discussion as part of the European project innovation and Employment in European Firms: Microeconometric Evidence.

Kang, Gyuho (2006), Technological Innovation and Job Creation, Economic Analysis, 12(1), pp. 53-75.

Lachenmaier, S. and Rottmann, H. (2011), Employment Effects of Innovation at the Firm Level, International Journal of Industrial Organization, 29(2), pp. 210-220.

Lachenmaier, S. and Rottmann, H., (2007), Employment effects of innovation at the firm level, Journal of Economics and Statistics, 227(3), pp. 254-272.

Lachenmaier, S. and Rottmann, H. (2015), Effects Of Innovation on Employment: A Dynamic Panel Analysis, CESifo Working Paper No. 2015.

Mun, Sungbae and Chun, Hyunbae (2008), The Effects of Innovation Activities on Employment: Evidence from Korean ICT Firms, Korean Journal of Industrial Organization, 16(1), pp.1-24.

Michelacci, C. and Lopez-Salido, D. (2007), Technology Shocks and Job Flows, Review of Economic Studies, 74(4), pp. 1195-1227.

Mortensen, D. and Pissarides, C. (1998), Technological Progress, Job Creation and Job Destruction, Review of Economic Dynamics, 1(4), pp. 733-753

Pissarides, C.(2000), Equilibrium Unemployment Theory, 2nd Edition, MIT Press.

Peters, B. (2004), employment effects of different innovation activities: microeconomic evidence, ZEW Discussion Paper, pp. 04-73

Rosenbaum, P.R. and Rubin (1983), The central role of the propensity score in observational studies for causal effects, Biometrika, 70(1), pp. 41-55. 
Rubin D. B. (1979), Using Multivariate Matched Sampling and Regression Adjustment to Control Bias in Observational studies", Journal of the American Statistical Association

Shin, Bumcheol, Song, Chiwoong and Choi, Kukhyeon (2012), Comparative Analysis of Employment Effects according to Types of Technological Innovation, Korean Corporation Management Association (KOCOMO), 19(6), pp. 75-91.

Utterback, J.M. and Abernathy, W.J. (1975). A Dynamic Model of Process and Product Innovation, Omega, The Int. Jl of Mgmt Sci., 3(6), pp. 639-656.

Verspagen, B. (2004), Innovation and jobs: A micro-and-macro perspective, ECIS Working Papers, 04(15), Eindhoven Center for Innovation Studies.

Vivarelli, M., Evangelista, R., and Pianta, M., (1996), Innovation and employment in Italian manufacturing industry, Research Policy, 25(7), pp. 1013-1026.

Zimmerman, V. (2008), The impact of innovation on employment in small and medium enterprises with different growth rates, ZEW Discussion Paper pp. 08-134.

Zimmerman, K. (1991), The Employment Consequences of Technological Advance: Demand and Labor Costs in 16 German Industries, Empirical Economics, 16(2), pp. 253-266. 